\title{
Biased Target Ion Beam Deposition and Nanoskiving for Fabricating NiTi Alloy Nanowires
}

\author{
Huilong Hou ${ }^{1,2} \cdot$ Mark W. Horn ${ }^{2}$ Reginald F. Hamilton ${ }^{1,2,3}$
}

Published online: 29 November 2016

(C) ASM International 2016

\begin{abstract}
Nanoskiving is a novel nanofabrication technique to produce shape memory alloy nanowires. Our previous work was the first to successfully fabricate NiTi alloy nanowires using the top-down approach, which leverages thin film technology and ultramicrotomy for ultra-thin sectioning. For this work, we utilized biased target ion beam deposition technology to fabricate nanoscale (i.e., sub-micrometer) NiTi alloy thin films. In contrast to our previous work, rapid thermal annealing was employed for heat treatment, and the B2 austenite to R-phase martensitic transformation was confirmed using stress-temperature and diffraction measurements. The ultramicrotome was programmable and facilitated sectioning the films to produce nanowires with thickness-towidth ratios ranging from 4:1 to 16:1. Energy dispersive $\mathrm{X}$-ray spectroscopy analysis confirmed the elemental $\mathrm{Ni}$ and Ti make-up of the wires. The findings exposed the nanowires exhibited a natural ribbon-like curvature, which depended on the thickness-to-width ratio. The results demonstrate nanoskiving is a potential nanofabrication technique for producing NiTi alloy nanowires that are continuous with an unprecedented length on the order of hundreds of micrometers.
\end{abstract}

Reginald F. Hamilton

rfhamilton@psu.edu

1 Multifunctional and Adaptive Material Laboratory, The Pennsylvania State University, University Park, PA 16802, USA

2 Engineering Science and Mechanics Department, The Pennsylvania State University, University Park, PA 16802, USA

3 Materials Research Institute, The Pennsylvania State University, University Park, PA 16802, USA
Keywords Nanofabrication - Biased target ion beam deposition $\cdot \mathrm{NiTi} \cdot$ Nanowires $\cdot$ Shape memory films

\section{Introduction}

Fabrication of shape memory alloys (SMAs) with nanometer dimensions is important for experimental exploration of extrinsic size effects on the martensitic transformation (MT) and concomitant shape memory responses, which can potentially validate simulated behaviors. To date, top-down fabrication using the focusedion beam has been used to produce pillar specimen geometries with two-dimensions of micrometer down to sub-micrometer scales [1-4]. Nano-compression using nanoindentation has been used for the deformation of SMA nanopillars [1-3]. Studies of nanopillars have uncovered size effects on shape memory behaviors. For example, ultrahigh superelastic hystereses exist at the nanoscale in contrast to bulk scale [4]. As the pillar diameter decreases below a limit $(\sim 200 \mathrm{~nm})$, the stress-induced martensitic transformation becomes suppressed [3]. Tensile deformation, however, has yet to be investigated for SMA nanopillars.

Bottom-up fabrication of SMA nanowires has transformative potential for tailoring the chemistry and microstructure of nanoscale SMAs. Furthermore, freestanding nanowires can be studied using fundamental tensile experimentation via microelectromechanical systems for in situ electron microscopy [5]. Nanowires have been fabricated using methods such as shadow deposition [17, 18], focused ion beam [6], dip-pen nanolithography [7], vapor-liquid-solid process [8,9], and template synthesis [10-12]. Indium-Thallium SMA nanowires have been successfully fabricated using a bottom-up template 
synthesis technique: the mechanical pressure injection method (MPIM). Melted materials were injected into an anodized aluminum oxide template to produce nanowires with diameters ranging from 10 to $650 \mathrm{~nm}[10,13]$. However, MPIM is limited to alloys with melting temperatures lower than the templates (e.g., $\sim 660^{\circ} \mathrm{C}$ for aluminum) and thus could be challenging for the flagship SMA NiTi $\left(\sim 1300{ }^{\circ} \mathrm{C}\right)$. In this work, we utilize a novel technique referred to as nanoskiving [14], which has potential applications to the diverse classes of SMAs including NiTi-based, Cu-based, and Fe-based compositions.

Nanoskiving combines thin film deposition with ultrathin sectioning via ultramicrotomy, and was introduced to fabricate gold nanowires in 2006 [15]. Since then, numerous materials have been successfully fabricated using nanoskiving such as metals [16, 17], ceramics [18], semiconductors $[18,19]$, polymers $[20,21]$, as well as sophisticated nanostructures such as high-aspect-ratio rings [22], heterojunctions [20], and arrays of crescents and coaxial cylinders [19]. Typical functional SMA thin films have thickness on the order of 1-10 microns [23-26]. Our previous work discovered that biased target ion beam deposition (BTIBD) can produce nanoscale thin films with an ultra-smooth surfaces [26], a minimal diffusion interface [27], and the absence of columnar-void morphology for promoting crystallization [28]. Recently, we demonstrated nanoskiving successfully for NiTi alloys [29], which was the first demonstration on any metallic alloy system. In that previous work, as-deposited, magnetron sputtered thin films were nanoskived, which produced $250-\mu \mathrm{m}$-long nanowires (in contrast to $\sim 10 \mu \mathrm{m}$ nanowires by other techniques) with $120 \times 90 \mathrm{~nm}$ cross-sectional dimensions. For the current work, we employed this novel BTIBD technique for thin film deposition, rapid thermal annealing (RTA) for crystallization, and nanoskiving for generation of nanowires.

\section{Experimental}

NiTi alloy thin films with $800 \mathrm{~nm}$ thickness and Ti-50.3 at.\% $\mathrm{Ni}$ composition were deposited using separate elemental Ni and Ti targets in the BTIBD system (4Wave Inc., Sterling, VA, USA). The BTIBD system is located at The Pennsylvania State University. The technique utilizes a high output, low-energy plasma source that promotes adatom mobility. Pulse-biasing on the targets facilitates controlling the film composition. Moreover, BTIBD uses low processing pressure $\left(10^{-4}\right.$ Torr $)$ in comparison to sputtering $\left(10^{-2}-10^{-3}\right.$ Torr $)$ which reduces backscattering during deposition. Deposition parameters including power calibration, processing pressure, target biasing and other processing parameters have been detailed in previous works [26, 28, 29]. Films were deposited on Si substrates, which were $4.2 \times 4.2$ and $25.4 \times 25.4 \mathrm{~mm}^{2}$ squares cut from a six-inch $\mathrm{Si}$ wafer. To crystallize the as-deposited thin films, a $600{ }^{\circ} \mathrm{C}, 10$-min heat treatment was carried out in a rapid thermal annealing furnace (RTA, Allwin21 Corp., Morgan Hill, CA, USA) at a ramp rate $30{ }^{\circ} \mathrm{C} / \mathrm{s}$.

The NiTi alloy thin films deposited on $25.4 \times 25.4 \mathrm{~mm}^{2}$ $\mathrm{Si}$ substrates were characterized using the substrate curvature measurement technique. The measurements were made using the FLX-2320, Tencor Instruments (KLATencor Corp., Manassas, VA, USA). The temperature was cycled between 25 and $80{ }^{\circ} \mathrm{C}$. The heating rate was $1{ }^{\circ} \mathrm{C} /$ min while natural cooling from 80 to $25^{\circ} \mathrm{C}$ typically lasted $\sim 1.5 \mathrm{~h}$. The substrate curvature measured at each temperature was converted to film stress using Stoney's equation and the conversion details have been reported elsewhere $[25,30]$. Film stress versus temperature was plotted and the results are shown in Fig. 1a. A negative slope results from the coefficient of thermal expansion (CTE) mismatch between the substrate and the film. The phase transformation corresponds to the change from a negative to positive slope. The stress due to the transformation can exceed that due to CTE mismatch and thus the slope becomes positive [31].

X-ray diffraction (XRD) was conducted at room temperature in order to confirm the crystal structure using a grazing incidence mode in an X-ray diffractometer (X'Pert MPD, PANalytical, Westborough, MA, USA) with a $\mathrm{Cu} \mathrm{K} \mathrm{K}_{\alpha}$ 1 X-ray source $\left(\lambda \mathrm{K}_{\alpha}=1.5418 \AA\right)$. The scan step was 0.026 degrees and the step time was $0.5 \mathrm{~s}$. The collected XRD spectra were indexed using Jade 2010 software (Materials Data Inc., Livermore, CA, USA). The indexing peaks are shown in Fig. 1b and the R-phase is identified with one major peak (300). The $\mathrm{Ti}_{2} \mathrm{Ni}$ phase is a precipitate that occurs during the heat treatment. The single (300) peak, instead of two split peaks (300) and (11-2), suggests preferential orientation, as previously reported in [32,33]. It is expected that the residual stress stabilizes the R-phase and thus conversion to $\mathrm{B} 19^{\prime}$ martensite is not observed. The transformation temperatures are $R_{\mathrm{s}}=61{ }^{\circ} \mathrm{C}$, $R_{\mathrm{f}}=44{ }^{\circ} \mathrm{C}, A_{\mathrm{s}}=48{ }^{\circ} \mathrm{C}$, and $A_{\mathrm{f}}=64{ }^{\circ} \mathrm{C}$. The stress magnitude changes by approximately $30 \mathrm{MPa}$ upon transformation. The thermal hysteresis defined by $A_{\mathrm{s}}-R_{\mathrm{S}}$ equals $4{ }^{\circ} \mathrm{C}$, which is comparable to the nearly $2{ }^{\circ} \mathrm{C}$ hysteresis that has been reported for the R-phase transformation in bulk samples [34, 35].

The nanoskiving technique is illustrated in Fig. 2. In step (a) of Fig. 2, a NiTi alloy thin film was deposited on a $4.2 \times 4.2 \mathrm{~mm}^{2} \mathrm{Si}$ substrate. The thin film underwent the same BTIBD deposition and heat treatment as the aforementioned film, which showed the R-phase transformation. Therefore, the same behavior and atomic crystal structure 
Fig. 1 a Film stress versus temperature in BTIBD NiTi alloy films after annealing at $600{ }^{\circ} \mathrm{C}$ for $10 \mathrm{~min}$. The transformation temperatures, $R_{\mathrm{S}}$, $R_{\mathrm{f}}, A_{\mathrm{s}}, A_{\mathrm{f}}$ are determined by the tangent method. b XRD spectra at room temperature
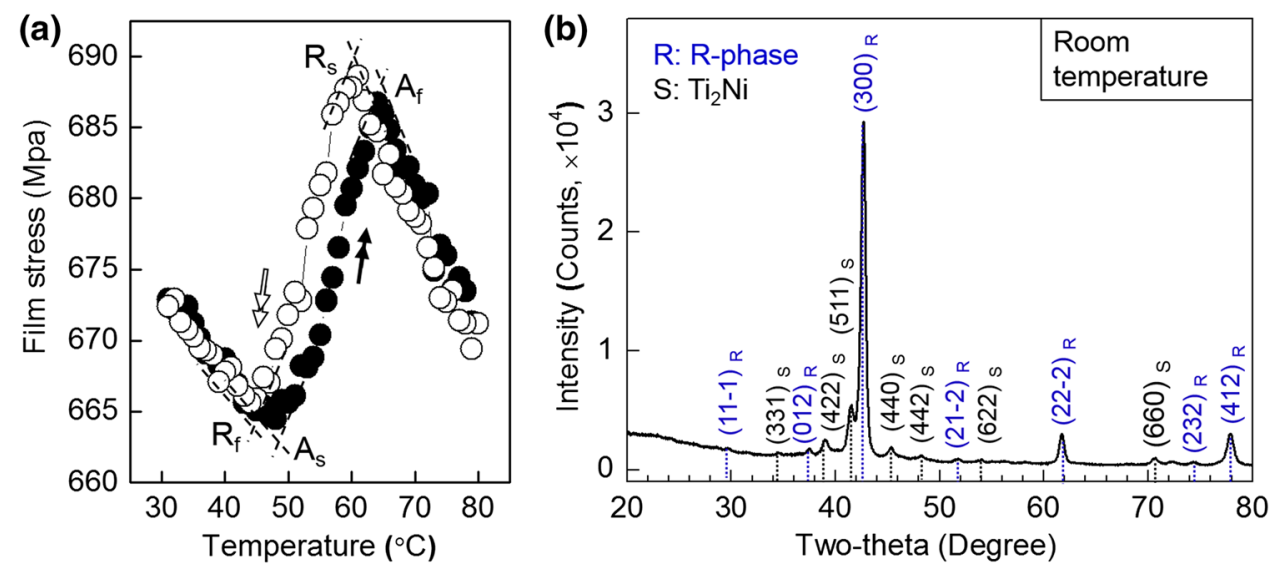

are expected. The thickness of the thin film was $800 \mathrm{~nm}$, which was dictated by the deposition time, and equals the thickness of nanowires. For step (b), epoxy was an eponate $12^{\mathrm{TM}}$ Embedding Kit (Ted Pella, Redding, CA, USA). The thin films naturally delaminated from the substrate. Delamination was likely due to stress relief [30] and facilitated mechanical transfer as peeling off was not necessary. The BTIBD NiTi alloy thin film was transferred into the epoxy liquid for complete enclosure, which was subsequently cured in an oven at $60{ }^{\circ} \mathrm{C}$ for about $12 \mathrm{~h}$. The rough cut in step (c) established the length of the nanowires. The epoxy/film/epoxy sandwich was cleaved using a razor blade into a block with one end trimmed into a cross section area of $1 \mathrm{~mm}$ by $1 \mathrm{~mm}$.

In the final step (d), slabs were sequentially sectioned from the block using an ultramicrotome (EM UC6, Leica Microsystems Inc., Buffalo Grove, IL, USA) with precise, automated control. The sectioning interval prescribed in the ultramicrotome established the width of the slab (and thus the nanowire). In contrast to the glass knife used in our previous work, the current work employs a diamond knife in order to maintain uniform contact between the knifeedge and the slab. In one session of sectioning, fourteen slabs were continually sectioned using a speed of cutting
Fig. 2 Schematic showing the process of nanoskiving to generate nanowires from BTIBD NiTi thin films. The dimensions of the nanowires are individually controlled: a the thickness is dictated by thin film deposition time; $\mathbf{c}$ the length is established by the rough cut distance; and $\mathbf{d}$ the width is determined by the sectioning interval (a) Deposit film

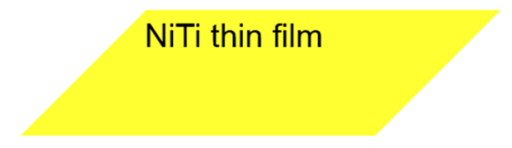

(b) Embedding

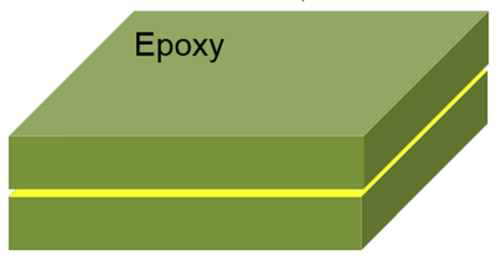

(c) Rough cut

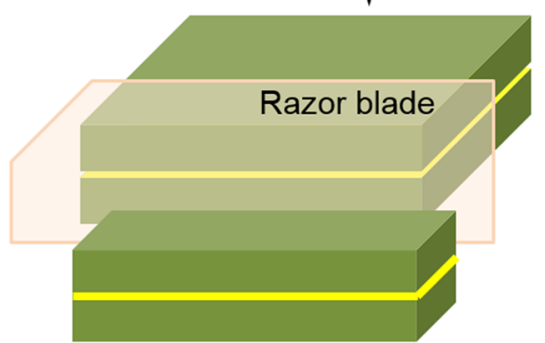

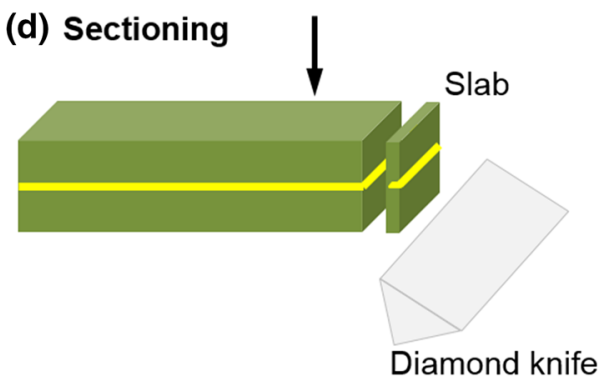

(e) Etching off epoxy

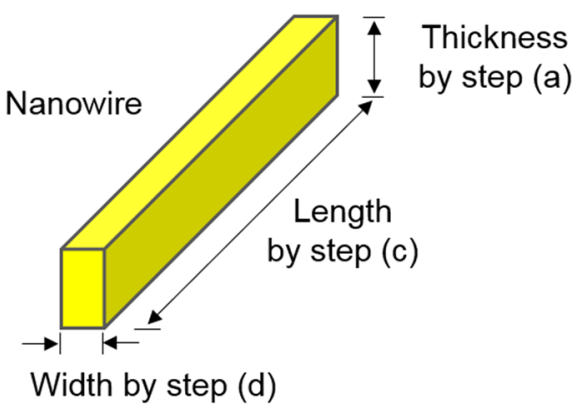


Fig. 3 a Bright-field and

b dark-field optical images of an

epoxy slab containing a NiTi

nanowire with $200 \mathrm{~nm}$ width.

The trace arises after the

nanowire is curled out of the

plane parallel to the epoxy slab

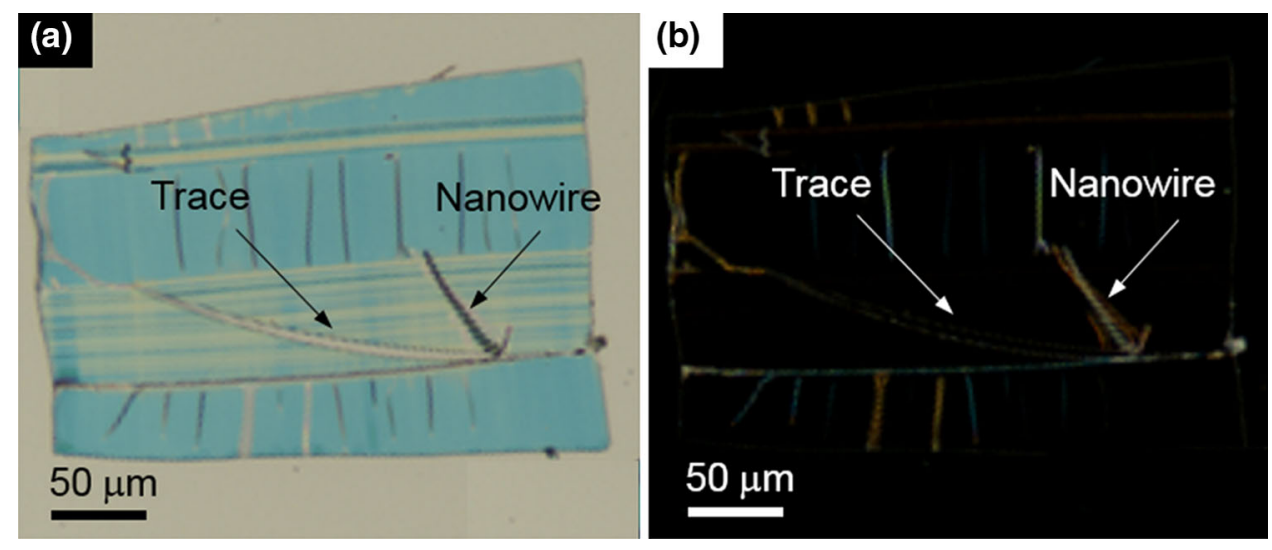

Fig. 4 Optical images of freestanding NiTi nanowires, after epoxy is etched, with differential widths generated from nanoskiving

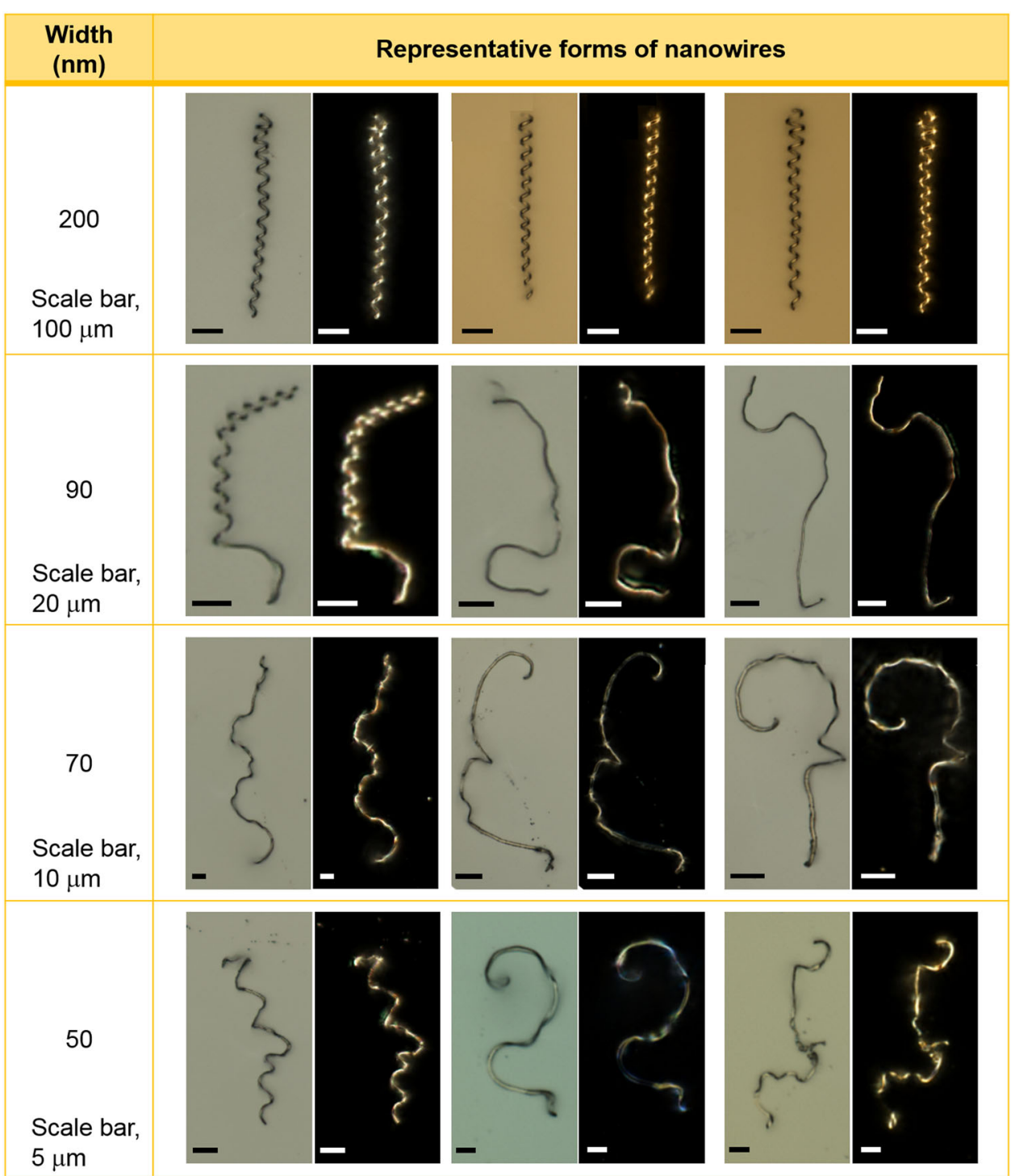

$1 \mathrm{~mm} / \mathrm{s}$. Of note is that the rate of sectioning slabs was $1 \mathrm{~Hz}$, and more than 500 slabs can be generated in $20 \mathrm{~min}$. The slabs were collected using a copper grid for transmission electron microscopy (TEM) analysis. Slabs for optical microscopy imaging were collected using $4.2 \times 4.2 \mathrm{~mm}^{2} \mathrm{Si}$ substrates. In order to expose the nanowires, residual epoxy was etched away in step (e) using a desktop plasma etcher (M4L, PVA TePla America 
Inc., Corona, CA, USA) under 550 mTorr pressure, 200 Watt power, and $150 \mathrm{sccm}$ oxygen for $18 \mathrm{~min}$.

One representative slab after sectioning in Fig. 2 was examined in an optical microscope (L200ND, Nikon Inc., Melville, NY, USA) and the images are in Fig. $3 a$ and b. The color of slabs can be used to estimate their width based on comparison to an interference card [36]. The color of the slabs in Fig. 3a corresponds to a width of $\sim 200 \mathrm{~nm}$ and matches the prescribed value during sectioning in the ultramicrotome. Ideally, the sectioned nanowires are expected to lie flat and parallel to the slab [20, 37]. The NiTi alloy nanowire in Fig. $3 a$ and $b$ is curled out of the plane of the epoxy slab. A trace is identified within the epoxy slab in Fig. $3 a$ and $b$ that denotes the region from which the nanowire curled out-of-plane.

\section{Results and Discussion}

A series of nanowires were sectioned from one block with differential widths prescribed. Representative nanowires are shown in Fig. 4. The lengths of the nanowires are on the order of $100 \mu \mathrm{m}$. For example, the nanowires with $90 \mathrm{~nm}$ widths are about $200-\mu \mathrm{m}$-long and the 200 -nm-wide nanowires are up to $1000 \mu \mathrm{m}$ long. For the $\sim 800$-nm-thick nanowires with widths of 200, 70, and $50 \mathrm{~nm}$ as in Fig. 4, the corresponding thickness-to-width ratio is $4: 1, \sim 11: 1$, and 16:1, respectively. The 200-nm-width nanowires have a spiraling, helical shape. For the $90 \mathrm{~nm}$ down to 50-nmwidth nanowires, straight segments are apparent along with large curvatures, markedly different from the spiraling, helical shape. The 90- and 70-nm nanowires have extended straight segments by comparison. The curved regions likely originate from residual stress after thin film deposition and subsequent release after sectioning and etching.

Free-standing nanowires were analyzed in a $200 \mathrm{kV}$ TEM (FEI Tecnai G20, Hillsboro, OR, USA) equipped with an energy dispersive X-ray spectroscopy (EDS) detector (EDAX, division of AMETEK, Berwyn, PA, USA). The results are shown in Fig. 5. In Fig. 5a, multiple nanowires are shown that are clustered on the $\mathrm{Cu}$ grid. Figure $5 \mathrm{~b}$ and $\mathrm{c}$, respectively, shows the views along the width direction and along the thickness direction of one nanowire. The nanowire has a $90 \mathrm{~nm}$ width and $800 \mathrm{~nm}$ thickness. In Fig. $5 \mathrm{~b}$ and c, the nanowire is continuous without breaks. The continuity over the length is consistent with our previous work [29], in which the nanowires had a cross section of $120 \mathrm{~nm}$ thickness by $90 \mathrm{~nm}$ width. The elements of $\mathrm{Ni}$ and $\mathrm{Ti}$ were detected by EDS analysis. In Fig. 5d, the signal of $\mathrm{Si}$ came from the detector and $\mathrm{Cu}$ came from sample holder and/or grid. Figure $5 \mathrm{~d}$ confirms the alloy nature without the presence of oxygen impurities.

Of note is that one can have control on the parameters of nanoskiving to influence the shape of generated nanowires shown in Fig. 4. Compared to perpendicular sectioning employed herein, parallel sectioning (the edge of thin films parallel to the direction of sectioning) tends to generate high rate of fragmentation, leading to nanowires with small length and can induce roughened surface morphology [18],
Fig. 5 a-c Bright-field TEM images of free-standing NiTi nanowires with $800 \mathrm{~nm}$ thickness and $90 \mathrm{~nm}$ width. A coordinate system is added in $\mathbf{b}$ and $\mathbf{c}$ to indicate the viewing direction: $L$ stands for length, $W$ for width, and $T$ for thickness $(L, W$, and $T$ are defined in Fig. 2e). Thus, $\mathbf{b}$ is a viewing direction parallel to $W$ and $\mathbf{c}$ is a viewing direction parallel to $T$. A representative EDS profile is shown in $\mathbf{d}$

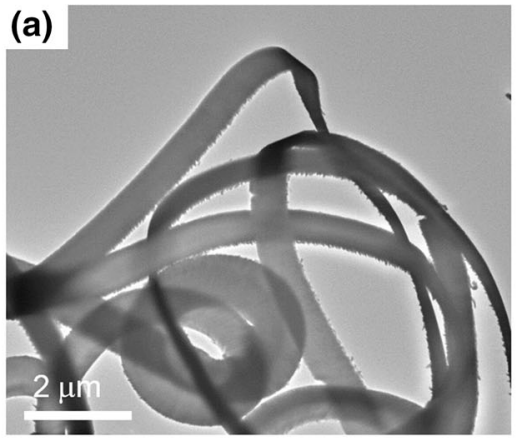

(c)

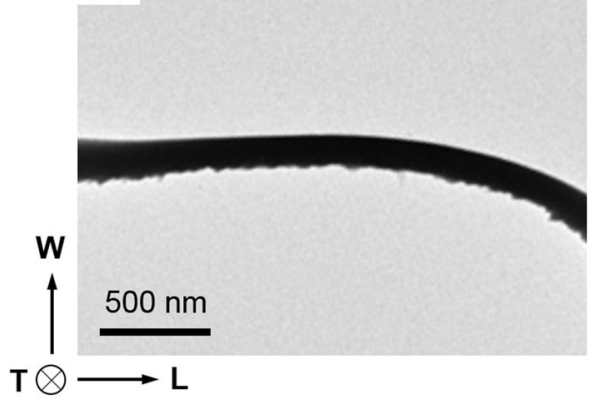

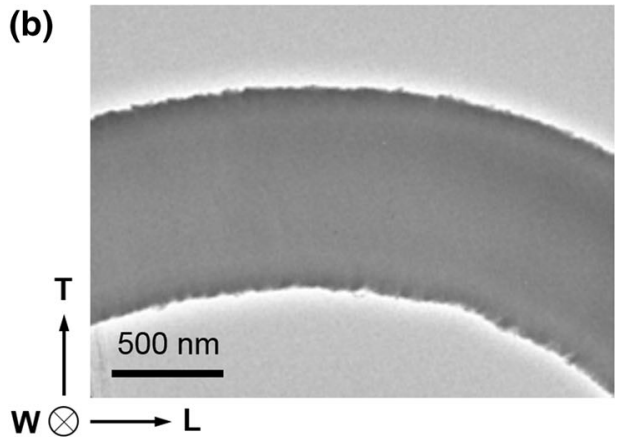

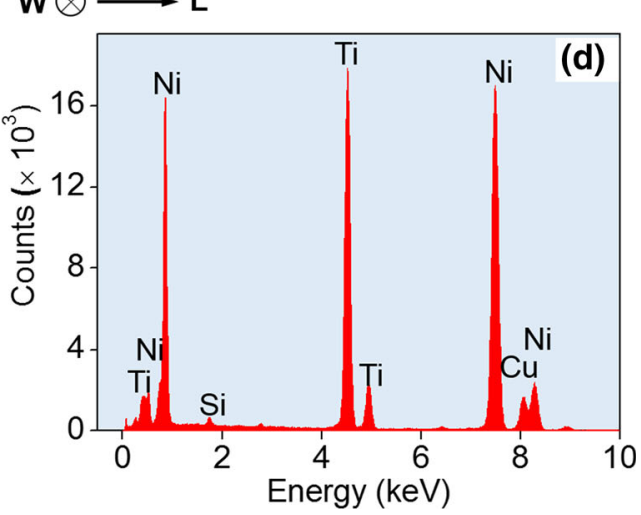


which could bring about distinct level of force during sectioning and thus shape of nanowires. The speed of cutting, which in a range from 0.1 to $8 \mathrm{~mm} / \mathrm{s}$ has been shown no effect on the rate of fragmentation $[18,38]$, could impose influence on the overall shape of nanowires. Controls on the $\mathrm{Ni}$ concentration in NiTi thin films and the level of heat treatment as well as the choice of embedding epoxy (Young's modulus larger than $1500 \mathrm{MPa}$ [14]) allow the extent of adjusting the properties of sectioning materials and ultimately influencing the geometric shape of product nanowires.

\section{Conclusions}

In summary, we utilized a novel thin film deposition technique, BTIBD, and the nanoskiving technique to fabricate NiTi alloy nanowires. In contrast to our previous work on sputtered NiTi films, the as-deposited BTIBD $\mathrm{NiTi}$ films herein underwent heat treatment in rapid thermal annealing. Moreover, the substrate curvature measurement confirmed the shape memory behavior, and the underlying martensitic crystal structure was determined to be the R-phase. Nanoskiving was shown to produce variable geometric cross-sectional dimensions. The length and width of the nanowires were controlled by a cutting/sectioning process. Nanowires exhibited a high aspect ratio of length to cross-sectional dimensions; with a fixed thickness of $800 \mathrm{~nm}$, wires were made with varied widths of 200, 90, 70 , and $50 \mathrm{~nm}$.

In conclusion, BTIBD and nanoskiving can produce NiTi alloys in the form of nanowires that are very long $(100-1000 \mu \mathrm{m})$ and free of oxygen impurities. The nanowires had high aspect ratio maybe described as nanoribbons. The cross-sectional dimension influences the form of the nanowires: 200-nm-wide nanowires have a spiraling shape while an extended straight segments exists for those nanowires with widths below $90 \mathrm{~nm}$. The 50-nm-wide nanowire was thermally cycled in TEM; however, the phase transformation was not evident. For the larger width wires such as $200 \mathrm{~nm}$, both thickness $(\sim 800 \mathrm{~nm})$ and width prohibited electron transparency. It is our contention that mechanical load may provide the necessary driving force to stress-induce the martensitic phase transformation. Future work must characterize the atomic structural dependence with temperature change, and explore novel nanoscale thermo-mechanical testing. Nanoskiving is capable of controlling the geometric dimensions of NiTi alloy nanowires and is advantageous as a generic nanofabrication method that is applicable to other shape memory materials, which paves pathways for design and development of advanced actuators and sensors in nanoelectromechanical systems (NEMS).
This work utilized nanoskiving to generate nanowires and control the nanoscale cross-sectional dimensions. However, microstructural length scales (e.g., grain or precipitate morphologies) are not investigated. Using heat treatment to control the intrinsic length scales allows for studying the effects of microstructure constraints and the interplay with geometric size. For nanoscale shape memory alloys, we can provide new understandings concerning the scaling of martensitic transformation morphology (e.g., width and periodicity of variants). Advanced nano-thermomechanical experimentation can be used to correlate that scaling to the shape memory properties (including recoverable strains and hysteric behaviors).

Acknowledgements The authors would like to thank Missy Hazen of The Huck Institutes of the Life Sciences, The Pennsylvania State University for assisting the thin sectioning in an ultramicrotome. The ultramicrotomy was performed at The Pennsylvania State University Microscopy and Cytometry Facility. The BTIBD, RTA, stress-curvature measurement technique, optical microscopy, transmission electron microscopy, and spectroscopy were conducted at The Pennsylvania State University node of the National Science Foundation-funded National Nanotechnology Infrastructure Network. This work was supported by the National Science Foundation under Grant No. CMMI 1538354

\section{References}

1. Ye J, Mishra RK, Pelton AR, Minor AM (2010) Direct observation of the NiTi martensitic phase transformation in nanoscale volumes. Acta Mater 58(2):490-498

2. San Juan J, No ML, Schuh CA (2008) Superelasticity and shape memory in micro- and nanometer-scale pillars. Adv Mater 20(2):272-278

3. Frick CP, Orso S, Arzt E (2007) Loss of pseudoelasticity in nickel-titanium sub-micron compression pillars. Acta Mater 55(11):3845-3855

4. San Juan J, No ML, Schuh CA (2009) Nanoscale shape-memory alloys for ultrahigh mechanical damping. Nat Nanotechnol 4(7):415-419

5. Desai AV, Haque MA (2007) Mechanical properties of $\mathrm{ZnO}$ nanowires. Sensor Actuat a-Phys 134(1):169-176

6. Matsui S, Ochiai Y (1996) Focused ion beam applications to solid state devices. Nanotechnology 7(3):247-258

7. Hong SH, Zhu J, Mirkin CA (1999) Multiple ink nanolithography: toward a multiple-pen nano-plotter. Science 286(5439):523-525

8. Wu YY, Yang PD (2001) Direct observation of vapor-liquid-solid nanowire growth. J Am Chem Soc 123(13):3165-3166

9. Zhu Y, Xu F, Qin QQ, Fung WY, Lu W (2009) Mechanical properties of vapor-liquid-solid synthesized silicon nanowires. Nano Lett 9(11):3934-3939

10. Phillips FR, Fang D, Zheng HX, Lagoudas DC (2011) Phase transformation in free-standing SMA nanowires. Acta Mater 59(5): 1871-1880

11. Haberkorn N, Condo AM, Sirena M, Soldera F, Lovey FC (2014) Single crystalline beta phase $\mathrm{Cu}-\mathrm{Zn}$ nanowires: synthesis and martensitic transformation. Mater Lett 124:256-260

12. Fricoteaux P, Rousse C (2014) Nanowires of $\mathrm{Cu}-\mathrm{Zn}$ and $\mathrm{Cu}-\mathrm{Zn}$ $\mathrm{Al}$ shape memory alloys elaborated via electrodeposition in ionic liquid. J Electroanal Chem 733:53-59 
13. Zheng HX, Luo ZP, Fang D, Phillips FR, Lagoudas DC (2012) Reversible phase transformations in a shape memory alloy In-T1 nanowires observed by in situ transmission electron microscopy. Mater Lett 70:109-112

14. Xu QB, Rioux RM, Dickey MD, Whitesides GM (2008) Nanoskiving: a new method to produce arrays of nanostructures. Acc Chem Res 41(12):1566-1577

15. Xu QB, Bao JM, Capasso F, Whitesides GM (2006) Surface plasmon resonances of free-standing gold nanowires fabricated by nanoskiving. Angew Chem Int Edit 45(22):3631-3635

16. Xu QB, Bao JM, Rioux RM, Perez-Castillejos R, Capasso F, Whitesides GM (2007) Fabrication of large-area patterned nanostructures for optical applications by nanoskiving. Nano Lett 7(9):2800-2805

17. Xu Q, Rioux RM, Whitesides GM (2007) Fabrication of complex metallic nanostructures by nanoskiving. ACS Nano 1(3):215-227

18. Lipomi DJ, Martinez RV, Rioux RM, Cademartiri L, Reus WF, Whitesides GM (2010) Survey of materials for nanoskiving and influence of the cutting process on the nanostructures produced. ACS Appl Mater Interfaces 2(9):2503-2514

19. Lipomi DJ, Kats MA, Kim P, Kang SH, Aizenberg J, Capasso F, Whitesides GM (2010) Fabrication and replication of arrays of single- or multicomponent nanostructures by replica molding and mechanical sectioning. ACS Nano 4(7):4017-4026

20. Lipomi DJ, Chiechi RC, Reus WF, Whitesides GM (2008) Laterally ordered bulk heterojunction of conjugated polymers: nanoskiving a jelly roll. Adv Funct Mater 18(21):3469-3477

21. Lipomi DJ, Chiechi RC, Dickey MD, Whitesides GM (2008) Fabrication of conjugated polymer nanowires by edge lithography. Nano Lett 8(7):2100-2105

22. Xu QB, Perez-Castillejos R, Li ZF, Whitesides GM (2006) Fabrication of high-aspect-ratio metallic nanostructures using nanoskiving. Nano Lett 6(9):2163-2165

23. Wang X, Vlassak JJ (2015) Thickness and film stress effects on the martensitic transformation temperature in equi-atomic NiTi thin films. Mech Mater 88:50-60

24. König D, Buenconsejo PJS, Grochla D, Hamann S, PfetzingMicklich J, Ludwig A (2012) Thickness-dependence of the B2B19 martensitic transformation in nanoscale shape memory alloy thin films: zero-hysteresis in $75 \mathrm{~nm}$ thick Ti51Ni38Cu11 thin films. Acta Mater 60(1):306-313

25. Fu YQ, Zhang S, Wu MJ, Huang WM, Du HJ, Luo JK, Flewitt AJ, Milne WI (2006) On the lower thickness boundary of sputtered TiNi films for shape memory application. Thin Solid Films 515(1):80-86

26. Hou H, Hamilton RF, Horn MW, Jin Y (2014) NiTi thin films prepared by biased target ion beam deposition co-sputtering from elemental Ni and Ti targets. Thin Solid Films 570:1-6

27. Hou H, Hamilton RF, Horn MW (2015) Structure and interfacial analysis of nanoscale TiNi thin film prepared by biased target ion beam deposition. J Vac Sci Technol A 33(4):040601

28. Hou H, Hamilton RF, Horn MW (2016) Crystallization and microstructure evolution of nanoscale NiTi thin films prepared by biased target ion beam deposition. J Vac Sci Technol B 34(1):010601

29. Hou H, Hamilton RF (2015) Free-standing NiTi alloy nanowires fabricated by nanoskiving. Nanoscale 7(32):13373-13378

30. Freund LB, Suresh S (2004) Thin film materials: stress, defect formation and surface evolution. Cambridge University Press, Cambridge

31. Fu YQ, Luo JK, Ong SE, Zhang S, Flewitt AJ, Milne WI (2008) A shape memory microcage of TiNi/DLC films for biological applications. J Micromech Microeng 18(3):035026

32. Sittner P, Landa M, Lukas P, Novak V (2006) R-phase transformation phenomena in thermomechanically loaded NiTi polycrystals. Mech Mater 38(5-6):475-492

33. Buenconsejo PJS, Zarnetta R, Young M, Brunken H, Mehta A, Ludwig A (2014) On the mechanism that leads to vanishing thermal hysteresis of the B2-R phase transformation in multilayered $(\mathrm{TiNi}) /(\mathrm{W})$ shape memory alloy thin films. Thin Solid Films 564:79-85

34. Gyobu A, Kawamura Y, Horikawa H, Saburi T (1999) Martensitic transformation and two-way shape memory effect of sputterdeposited Ni-rich Ti-Ni alloy films. Mater Sci Eng A 273-275:749-753

35. Gyobu A, Kawamura Y, Saburi T, Asai M (2001) Two-way shape memory effect of sputter-deposited Ti-rich Ti-Ni alloy films. Mater Sci Eng A 312(1-2):227-231

36. Malis TF, Steele D (1990) Ultramicrotomy for materials science. Mater Res Soc Symp Proc 199:3-50

37. Lipomi DJ, Ilievski F, Wiley BJ, Deotare PB, Loncar M, Whitesides GM (2009) Integrated fabrication and magnetic positioning of metallic and polymeric nanowires embedded in thin epoxy slabs. ACS Nano 3(10):3315-3325

38. Jésior JC (1986) How to avoid compression II. The influence of sectioning conditions. J Ultrastruct Mol Struct Res 95(1):210-217 